\title{
O LEGADO DAS COLONIZAÇÕES DA AMAZÔNIA ORIENTAL: REDES DE AGLOMERADOS RURAIS OU REDES PROTO- URBANAS?
}

\section{THE COLONIZATIONS LEGACY OF ORIENTAL AMAZON: RURAL SETTLEMENTS NETWORK OF PROTO URBAN NETWORKS?}

\author{
Giselle Fernandes de Pinho ${ }^{1}$ \\ Universidade Estadual de Campinas, Campinas, SP, Brasil, fpgiselle@ gmail.com \\ Ana Cláudia Duarte Cardoso ${ }^{2}$ \\ Universidade Federal do Pará, Belém, PA, Brasil, aclaudiacardoso@ gmail.com
}

\begin{abstract}
Resumo
Este artigo assume estudos de caso nos Municípios de Moju e Acará para investigar uma rede de pequenas aglomerações que compõem o território rural do nordeste paraense. Normalmente invisível aos órgãos oficiais e não considerada no desenho das políticas públicas rurais e urbanas, esses aglomerados efetivamente estruturam o território rural, como pode ser apreendido por meio de cartografia social. O objetivo deste artigo é relacionar os níveis hierárquicos dessa rede de aglomerados rurais aos resquícios das políticas colonizadoras. A metodologia utilizada foi qualitativa voltada para a análise de padrões sócio-espaciais, utilizando como ferramentas a cartografia social e a teoria dos grafos para gerar um gradiente urbano-rural e os níveis de hierarquia da rede. Apesar da prevalência de funções agrárias, assumidas como ponto de partida da colonização realizada nos anos 1970, observa-se a disseminação de aglomerados rurais hierarquizados por centralidade, disponibilidade de serviços, estratégias de subsistência e coesão social, que articulam usos rurais a expectativas de consumo e acesso às políticas públicas normalmente associadas ao universo urbano, conectando esses dois mundos. O resultado de tantas superposições é um território híbrido cuja morfologia e padrão socioespacial em rede são pouco compreendidos e valorizados tanto pelo setor público quanto pela iniciativa privada.
\end{abstract}

Palavras-chave: Amazônia. Colonização. Morfologia Urbana. Rede de Aglomerados. Urbanismo Rural

\begin{abstract}
This article assumes case studies in Moju and Acará Municipalities to investigate a small network of settlements that constitutes the rural area of northeastern Pará. Normally invisible to official bodies and not considered in the design of rural and urban public policies, these settlements effectively structure the rural area, as it can be grasped through social mapping. The purpose of this article is to relate hierarchical levels of the rural settlements network to the remnants of colonial policies. The methodology was qualitative focused on the analysis of socio-spatial pattern, using as tools social mapping and graph theory to generate an urban-rural gradient and the hierarchy levels of the rural settlements network. Despite the prevalence of agrarian functions, taken as a starting point of colonization performed in the 1970s, it is observed the spreading of rural settlements classified by centrality, availability of services, livelihood strategies and social cohesion, articulating rural uses to consumer expectations and access to public policies normally associated with the urban universe, connecting these two worlds. The result of so many superpositions is a hybrid territory, which morphology and networks' sociospatial patterns are barely understood and valued by both public and private sectors.
\end{abstract}

Keywords: Amazon. Colonization. Urban Morphology. Settlements Networks. Rural Urbanism.

\section{How to cite this article:}

PINHO, Giselle Fernandes de; CARDOSO, Ana Cláudia Duarte. O legado das colonizações da Amazônia oriental: redes de aglomerados rurais ou redes proto-urbanas? PARC Pesquisa em Arquitetura e Construção, Campinas, SP, v. 7, n. 1, p. 35-45, mar. 2016. ISSN 1980-6809. Disponível em: <http://periodicos.sbu.unicamp.br/ojs/index.php/parc/article/view/8646107>. Acesso em: 12 ago. 2016. doi:http://dx.doi.org/10.20396/parc.v7i1.8646107. 


\section{Introdução}

O período militar empreendeu a colonização da Amazônia assumindo a falsa premissa de que a região era um deserto humano. As propostas do PIN - Programa de Integração Nacional (1970), implementadas pelo INCRA - Instituto Nacional de Colonização e Reforma Agrária, foram de colonização dirigida e semi-dirigida, alinhadas com o arcabouço teórico Christalleriano, inspirado na hierarquia espacial e econômica da rede de cidades existentes na Alemanha dos anos 1930 e difundida através da Teoria do Lugar Central (BESSA, 2012), e com as recomendações da Conferência do Habitat I, realizada em Vancouver em 1976, que assumiam a ação estatal forte como condição para a distribuição equilibrada da industrialização (e urbanização) do país (ANTONUCCI, 2009). Neste contexto, a colonização ao longo da Rodovia Transamazônica contou com a concepção de uma proposta de Urbanismo Rural (CAMARGO, 1973) que demonstrava o quanto um processo, a primeira vista assumido como agrário, já nascia urbano, na medida em que havia a expectativa de que a população migrante, atraída para os projetos de assentamento rural, teria acesso à terra, moradia e serviços públicos através de uma rede hierarquizada de aglomerados urbanos: agrovilas, agrópolis e rurópolis (Figura 1) de clara inspiração na citada Teoria do Lugar Central.

Figura 1 - Esquema da rede de aglomerados de acordo com a teoria do urbanismo rural

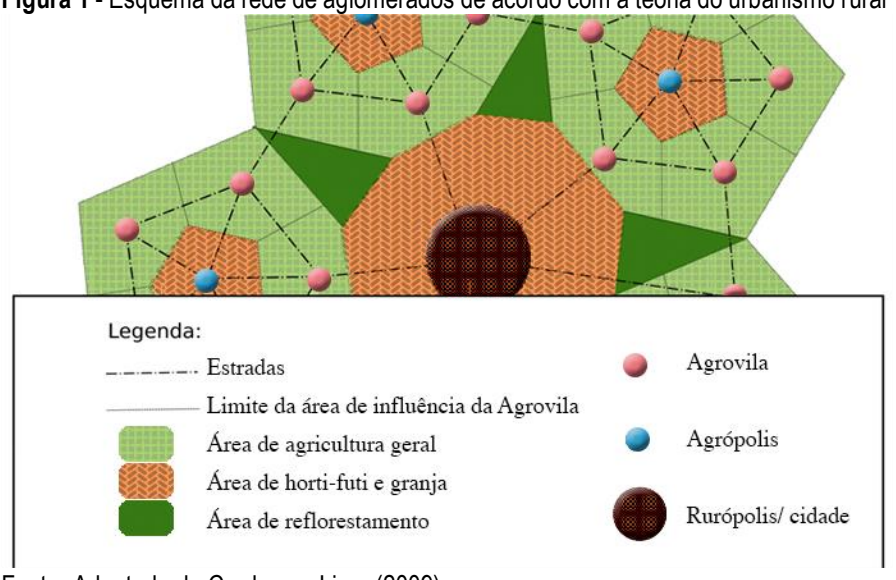

Fonte: Adaptado de Cardoso e Lima (2009)

A crise dos anos 1980 não permitiu que ocorresse a implantação dos núcleos urbanos conforme planejado, havendo apenas o requerimento da população rural para a implantação de núcleos urbanos improvisados nas localizações que foram definidas na proposta oficial e que originaram as atuais cidades de Brasil Novo, e Medicilândia (BECKER, 2013; MEDICILÂNDIA, 2014).

A parte da proposta do INCRA efetivamente implantada foi superposta ao padrão de dispersão de população já existente, implantados em processos de colonização de séculos anteriores.

\section{As colonizações da Amazônia e suas respectivas estratégias de uso e ocupação do território}

O primeiro processo de colonização da Amazônia, em especial no Nordeste Paraense, no período colonial (século XVI) se baseou em uma 'estratégia fluvial', de ocupação de pontos estratégicos ao longo do Rio Amazonas e seu efluentes (CASTRO, 2009), para defesa do território, captura e escravização de índios, exploração de drogas do sertão e produção de cacau e tabaco (CHAMBOULEYRON, 2006). Essas ocupações ocorreram em dois momentos: de 1616 a 1750 (ocupação através das missões e fortins); e de 1750 a 1800 (Período Pombalino).

Estas povoações eram compostas basicamente de aparato militar (fortim), aparato religioso (Igreja e propriedades agrícolas das missões), e algumas casas. Uma das principais diferenciações entre as povoações do período jesuíta e do período Pombalino é a especialização do uso da terra e a miscigenação induzida da população. $O$ aparato religioso perdeu influência e as povoações passaram a ter padrões espaciais que facilitaram as operações militares e o atendimento das necessidades civis (BECKER, 2013).

À época das missões, a população dessas povoações trabalhava com a coleta extrativa de produtos exóticos como o cravo e a salsaparrilha, de madeiras nobres, frutas e caça. $O$ vínculo com a terra era produtivo, ou seja, não havia propriedade fundiária (HEBETTE; MOREIRA, 2004; SCHMINK; WOOD, 2012). No período Pombalino, as iniciativas de comércio e exportação da Companhia do Grão-Pará e Maranhão, tentou alavancar a agricultura com incentivos, mas ainda foi sustentada pelo extrativismo. $\mathrm{O}$ comércio volante operado por embarcações chamadas "regatões" foi estabelecido.

O segundo período de colonização ocorreu durante o ciclo da borracha. Devido a mão de obra local estar empregada nos seringais, as novas colônias tinham por objetivo a produção de gêneros alimentícios como arroz, milho, feijão, mandioca, cana-de-açúcar, café e algodão. Essa ocupação foi marcada pela implantação de colônias tanto de migrantes de outras regiões do pais quanto de estrangeiros. A primeira foi criada em 1873 por iniciativa do Governo do Estado do Pará com a implantação de colônias de nordestinos, cuja principal produção era a farinha de mandioca que abastecia tanto Belém quanto a Região Nordeste. Em 1875 as primeiras colônias de imigrantes japoneses foram fixadas na região bragantina, com fracasso da maioria (HOMMA, 2011).

O terceiro período é o da colonização militar, anteriormente apresentado, e que se caracteriza pela superposição de padrões territoriais e produtivos. É o período que nega o extrativismo e o saber tradicional a 
respeito da resiliência dos recursos naturais e avança na apropriação da terra para usos produtivos modernos (plantation, pecuária, exploração de madeira e mineral).

A interação entre as novas colônias do período militar e os aglomerados já existentes geraram o que Hébette e Moreira (2004) identificaram efetivamente como redes de pequenas aglomerações rurais, articuladas a aglomerações maiores provedoras dos serviços mais especializados de que a população necessitava. Os migrantes não inseridos nos projetos oficiais de colonização adotaram uma referência "urbana" de centralidade quando se estabeleceram ao longo das estradas de acesso, para oferta de serviços normalmente demandados nos aglomerados e nos lotes rurais. Diversas "proto-urbes" - pequenos povoados e vilas -, surgiram espontaneamente nas vias recém-implantadas. Estas microcentralidades acabaram por valorizar aqueles núcleos urbanos pré-existentes, originados a partir da acessibilidade fluvial, mas que passaram a contar também com um novo acesso terrestre (rodoviário), enquanto que os núcleos mantidos estritamente ribeirinhos tornaram-se isolados nas margens dos rios, com tendência de encolhimento (HÉBETTE; ACEVEDO, 1979, PEREIRA, 2006).

\section{A formação do padrão espacial territorial atual}

As "proto-urbes" foram posicionadas próximas de fontes de água em um primeiro momento, constituídas por "uma ou duas dezenas de casas com sua igreja ou templo rústico, sua escola, seu lugar de reunião ou uma construção de uso diversificado" (HÉBETTE; ALVES; QUINTELA, 2004 p.108).

Com a fixação e o melhoramento relativo das condições de vida, esses aglomerados receberam pontos comerciais viabilizando uma certa autonomia à suas populações, quanto ao atendimento de grande parte de suas necessidades básicas, porém como dizem Hébette e Moreira (2004, p. 117), elas:

(...) esperam uma complementaridade de um centro mais complexo, reunindo a administração, os comércios (especialmente as inúmeras farmácias), os postos de saúde, uma escola secundária, os prédios religiosos, a sede do sindicato, artesanatos e pequenas indústrias (serrarias e olarias).

Guerra (2015) destaca esses equipamentos como estruturadores da sociabilidade em áreas rurais, e que ao fim e ao cabo conectam a população rural dispersa aos processos de urbanização, tanto pelo viés do consumo (através do acesso ao mercado) quanto pelo acesso a cidadania (através do acesso à escola, posto de saúde, espaço de lazer), ainda que relativamente isoladas, tais populações modificam hábitos e valores na medida em que são alcançadas pelo fenômeno da urbanização extensiva discutido por Monte-Mor (2014), que destaca que na
Amazônia a fronteira já nasceu urbana na medida em que os colonos almejavam, desde a chegada, um lote rural e um lote na agrovila ou na cidade.

Os aglomerados formaram gradativamente uma rede, cujos nós foram se especializando à medida que podiam oferecer mais serviços. Essas proto-urbes e/ou aglomerados rurais, são formalmente reconhecidos pelo IBGE - Instituto Brasileiro de Geografia e Estatística, através de classes de aglomerados rurais, definidas para o enquadramento da situação domiciliar rural, necessariamente localizados fora da área legalmente definida como urbana, e constituídos por arruamento reconhecível e área construída com edificações permanentes e adjacentes (IBGE, 2014). O IBGE classifica os aglomerados rurais pela localização em relação à área urbana e pelo porte de serviços e estabelecimentos disponível nos aglomerados.

No que se refere à localização, o IBGE define as classes: 1) Aglomerado Rural de Extensão Urbana, aqueles que se localizam a menos de $1 \mathrm{~km}$ de distância da área urbana; 2) Aglomerado Rural Isolado, aqueles que se localizam a distância igual ou superior a $1 \mathrm{~km}$ da área urbana e; 3) Rural, Exclusive Aglomerado (Local), constituído por um conjunto de domicílios que não fazem parte de nenhuma das outras categorias de aglomerado rural do IBGE.

A caracterização quanto ao porte diz respeito principalmente aos aglomerados rurais isolados. São classificados como Povoado aqueles que possuem obrigatoriamente pelo menos 1 (um) estabelecimento comercial de bens de consumo, e dois dentre os seguintes: 1 (um) estabelecimento de ensino de $1^{\circ}$ grau, 1 (um) posto de saúde (todos com atendimento regular) e 1 (um) templo religioso de qualquer credo. $\mathrm{O}$ aglomerado também não pode ter caráter privado ou empresarial (pertencer a um único dono) e seus moradores devem exercer atividades produtivas (primária, secundária ou terciária) na própria localidade ou fora dela; do contrário o aglomerado é caracterizado como Núcleo. Os aglomerados que não possuem caráter privado ou empresarial e não possuem em todo ou em parte os serviços e equipamentos definidores de povoado são, por sua vez, categorizados como Lugarejos.

Por fim, na categoria de Rural Exclusive Aglomerados, estão as propriedades rurais, os lugares e pequenos aglomerados, que possuindo um nome pelo qual são conhecidos, não possuem serviços e estabelecimentos (IBGE, 2014).

A observação empírica revelou a relevância de tipologias sócio espaciais capazes de refinar as classes adotadas pelo IBGE. Do ponto de vista social observou-se que laços familiares e vínculo sindical podem determinar a estrutura 
espacial dos aglomerados. Quanto fortes, favorecem o agrupamento (organização espacial) de casas em torno das instituições (escola, igreja/templo, campo de futebol), formando o que foi denominado na pesquisa de aglomerados-agrupados; quando essas dimensões são fracas ocorre maior dispersão das moradias ao longo das vias, favorecendo também a dispersão das instituições e formação do que se chamou aglomerados-rua. Ambas as tipologias podem ocorrer em uma mesma área, por exemplo, nos assentamentos formais onde há uma agrovila, que se constitui em um aglomerado-agrupado, pode existir, ao longo das vicinais e ramais, moradias dispersas ao longo de seus eixos, que são percebidas como comunidades, e foram assumidas como aglomerados-rua (HÉBETTE; ALVES; QUINTELA, 2004; PINHO, 2015).

\section{0 desenho da pesquisa}

Séculos de políticas colonizadoras, o universo rural amazônico resultou num amálgama formado por extensas fazendas, pequenos lotes de agricultores familiares, pequenos aglomerados dispersos ao longo dos rios, estradas vicinais, ramais e rodovias, todos articulados por uma rede de mobilidade, que é entendida neste estudo como uma trama, que superpõe modos de vida e condições socioeconômicas e ambientais diversas, mas sujeitas a fortes assimetrias quanto ao acesso às políticas públicas.

Para explorar esse fenômeno, uma rede de aglomerados rurais nos municípios do Moju e Acará, ambos localizados no nordeste Paraense, foi assumida como estudo de caso para ampliar a compreensão de como a população residente nesses aglomerados se articula com e no território. Este artigo tem como objetivo identificar os níveis hierárquicos dessa rede e relacioná-los aos resquícios das políticas colonizadoras, de modo a subsidiar políticas públicas dirigidas a esses territórios, a partir de uma visão de gradientes, alternativamente à antiga visão dicotômica de urbano ou rural. Espera-se que tais contextos sejam visto como áreas povoadas por uma população que escolhe viver em pequenos aglomerados, mas que também deseja qualidade de vida e respeito a sua identidade.

A grande extensão dos municípios de Moju e Acará determinou uma seleção de amostras. As localidades estudadas no Moju foram: o Assentamento Calmaria II, formado por cinco comunidades; a Vila Cardoso, formada por uma comunidade; e a Localidade Lírio dos Vales, formada por duas comunidades. No município do Acará foi estudada a localidade São Lourenço, formada pelos assentamentos Boa Esperança, Bom Futuro e Fortaleza, que juntos formam um conjunto de 15 comunidades; porém dessas 15 , apenas 7 foram representadas nas oficinas, e somente 5 produziram suas cartografias sociais.
A abordagem dos padrões sócio espaciais foi viabilizada por métodos qualitativos e informações secundárias. Foram assumidos como fontes os dados primários obtidos em campo, dados censitários, imagens de satélite e o georeferenciamento de pontos de interesse. O percurso metodológico consistiu: no trabalho de campo para a coleta dos dados primários realizado através das oficinas para elaboração de cartografias sociais; na elaboração de redes de deslocamento a partir dos depoimentos dos habitantes e do suporte da Teoria dos Grafos (PINHO, 2012); na elaboração de gradientes urbano-rural a partir da análise dos dados e da quantificação das distâncias.

As etapas do trabalho de campo realizadas em 2014 tiveram três momentos importantes: o primeiro contato com as comunidades para o reconhecimento da área através de reuniões com as comunidades, aproveitando a agenda de grupos de trabalho promovidos pela empresa Biopalma $^{1}$ na região, a identificação das lideranças das comunidades; e a participação em oficinas em que a população se apresentou e desenhou os mapas do território em que vivem, representando suas casas, os estabelecimentos de comércio e serviço existentes na comunidade, o que a comunidade possuía em termos de produção agrícola, vias de acesso e os recursos naturais disponíveis (Figura 2).

Figura 2 - Confecção das cartografias sociais durante as oficinas em: (A) Vila Boa esperança; (B) Vila Cardoso; (C) Vila Lírio dos Vales e (D) Agrovila Israel

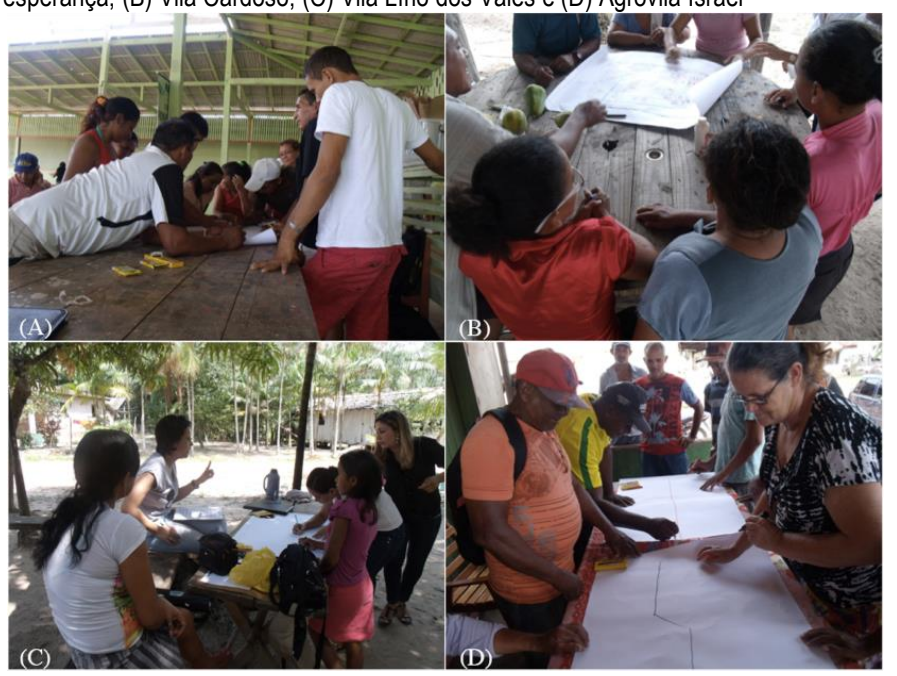

Fotos: Pinho (2015 p.63)

No período entre os meses de junho e setembro foi realizada uma oficina em cada localidade de estudo, resultando em 13 cartografias sociais, uma para cada comunidade participante na elaboração e apresentação das cartografias, conforme informado no quadro 1 . 
Quadro 1 - Quantidade de cartografias por localidade estudada

\begin{tabular}{|c|c|}
\hline Local da oficina & Quantidade de mapas \\
\hline Vila Cardoso & 1 \\
\hline Localidade Lírio dos Vales & 2 \\
\hline Assentamento Calmaria II & 5 \\
\hline Localidade São Lourenço & 5 \\
\hline
\end{tabular}

Fonte: Adaptado de Pinho (2015)

As informações foram sistematizas de acordo com as seguintes fases: caracterização de cada aglomerado estudado; preparo de grafos de deslocamento; desenho das redes; quantificação das distâncias; classificação dos aglomerados dentro do gradiente urbano-rural e identificação dos fluxos entre urbano e rural. Os dados deste artigo apoiam-se principalmente nas cartografias sociais e literatura revisada.

\section{0 entrelaçamento de práticas, formas e processos urbanos e rurais}

$\mathrm{O}$ gradiente urbano-rural desenvolvido na pesquisa identificou quatro níveis hierárquicos (A, B, C e D), sendo dois deles compostos por aglomerados considerados rurais (A e B) e os outros dois por aglomerados urbanos (C e D). Porém uma avaliação mais detalhada da morfologia de cada aglomerado rural aponta para a existência de uma sub-hierarquia com cinco níveis de aglomerados rurais:

O nível mais rudimentar da hierarquia, Nível A, é composto por aglomerados compostos por um pequeno conjunto de moradias relativamente próximas umas às outras, porém sem um adensamento evidente. Os serviços presentes variam entre um templo religioso ou escola de ensino fundamental ( $1^{\mathrm{a}}$ a $4^{\mathrm{a}}$ séries); com rara ocorrência de pontos comerciais. Normalmente estes aglomerados se localizam em ramais de ramais ou ramais de madeireiro, ou seja, vias estreitas abertas por maquinário pesado que não comportam o transito de automóveis (Figura 3).

Figura 3 - Representação do Nível A da rede de aglomerados
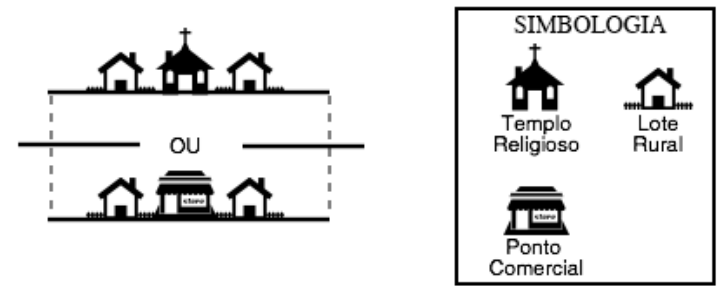

Fonte: Os autores

O nível seguinte, Nível $\mathrm{B}$, é composto por aglomerados um pouco maiores, com uma ou duas dezenas de moradias permanentes e adensamento evidente ao longo do arruamento principal. Os serviços variam entre um templo religioso e um pequeno ponto comercial ou um templo e uma escola de ensino fundamental $\left(1^{\mathrm{a}}\right.$ a $4^{\mathrm{a}}$ séries $)$; estes aglomerados se localizam em ramais reconhecidos, com arruamento oficial, e em alguns casos contém mais de um ponto comercial (Figura 4).

Figura 4 - Representação do Nível B da rede de aglomerados

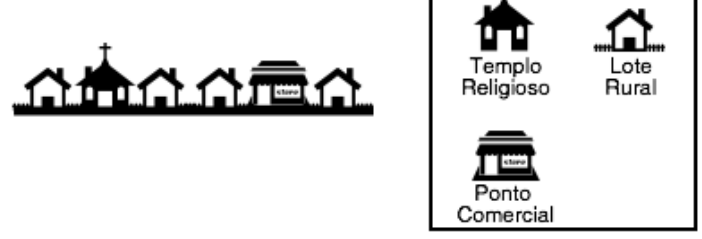

Fonte: Os autores

É comum nestes níveis que as moradias e os serviços sejam distribuídos em pequenos agrupamentos espalhados por uma grande área, como é o caso das comunidades chamadas de colônias em Acará-PA (Colônia dos Bianos e Vila Corinthians são exemplos do primeiro nível, Vila Bucaia e Vila Betel são exemplo do segundo nível), ou do Ramal Água Preta na Comunidade Água Preta, em Moju (Figura 5).

Figura 5 - Exemplo do posicionamento dos aglomerados dentro dos primeiro e segundo níveis

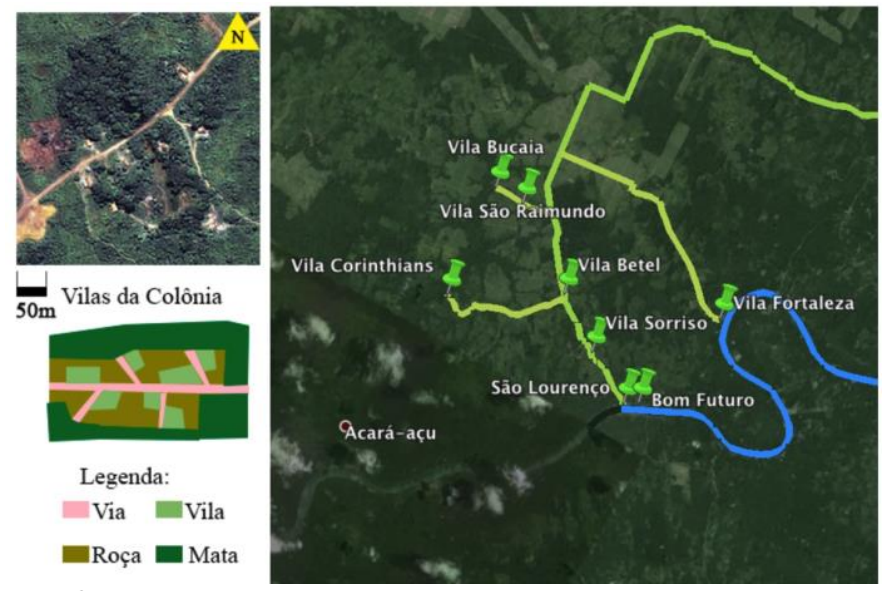

Fonte: Os autores

No terceiro nível, Nível C, da hierarquia os aglomerados estão localizados em ramais, estradas vicinais reconhecidas pelo arruamento oficial. Contam com uma escola de ensino fundamental ( $1^{\mathrm{a}}$ a $4^{\mathrm{a}}$ séries), sendo que em algumas localidades os equipamentos contam com quadras poliesportivas ou área aberta adjacente para fins esportivos; possuem uma quantidade maior tanto de templos religiosos quanto de estabelecimentos comerciais (cantinas comunitárias e bares nos ramais; lojas de confecção, açougues e minimercados nas vicinais. Neste nível a morfologia permite a distinção dos aglomerados em dois tipos básicos já apresentados na sessão anterior: Aglomerados-agrupados e Aglomerados-rua (Figura 6). 
Figura 6 - Representação do Nível $C$ da rede de aglomerados

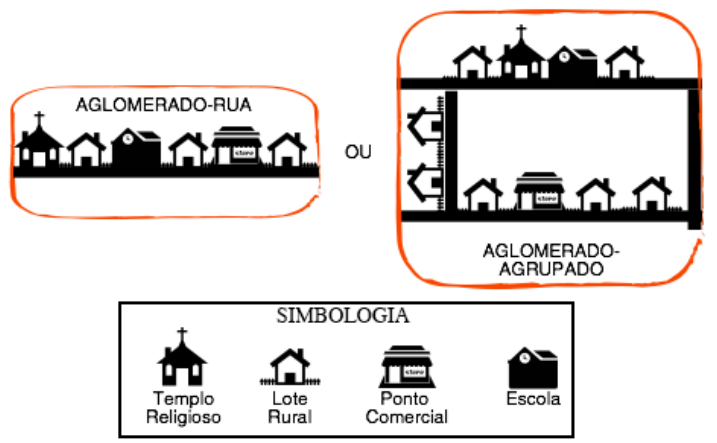

Fonte: Os autores

A diferenciação básica entre esses dois tipos reside no perfil viário e na localização dos serviços e instituições. Nos aglomerados-rua não existe um sistema de ruas, as instituições e comércios estão localizados ao longo de um único eixo viário de forma dispersa, entremeados das moradias permanentes. Como exemplo, tem-se a Vila Lírio dos Vales, Moju-PA (Figura 7).

Figura 7 - Vila Lírio dos Vales como exemplo de aglomerado-rua
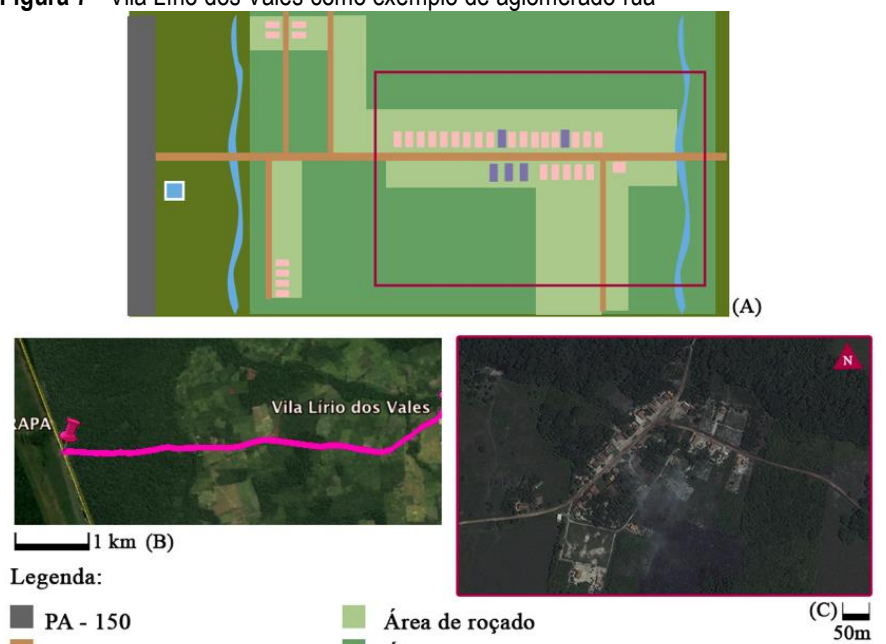

Legenda:

PA - 150

Vicinais e ramais

- Área de roçado

- Área de floresta secundária

(C)

Propriedades particulares

- Área de floresta primária

$\square$ Equipamentos comunitários $\square$ Prédio da EMBRAPA

Fonte: Pinho (2015, p 80)

Nos aglomerados-agrupados existe uma insipiente rede viária na qual os arruamentos formam uma ou mais quadras e os serviços e comércios se encontram em um ponto relativamente central. Como exemplo, tem-se a Vila Tracauateua, Moju-PA (Figura 8).
Figura 8 - Vila Tracauateua como exemplo de aglomerado agrupado

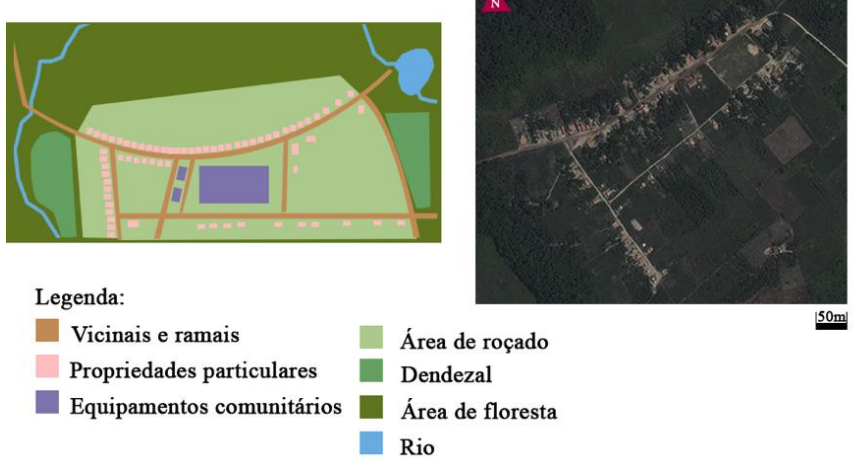

Fonte: Pinho (2015, p 81)

O quarto nível hierárquico, Nível $\mathrm{D}$, os aglomerados rurais são mais complexos, notadamente sempre se configurando em aglomerado-agrupado onde os serviços e os pontos comerciais ganham maior destaque e diversificação. Nestes aglomerados é possível encontrar comércios especializados, como açougues, lojas de roupa, pequenos serviços de conserto e mercearias, em sua maioria localizados ao longo da via principal ou próximo à entrada da vila. Os serviços de educação também se localizam em pontos centrais, e em alguns casos em pontos mais protegidos em vias secundárias. O sistema de ruas também se torna mais complexo, gerando uma quantidade maior de quadras. É composto por aglomerados localizados ao longo das vicinais ou às margens de importantes rios da região (Figuras 9 e 10).

Figura 9 - Representação do Nível D da rede de aglomerados

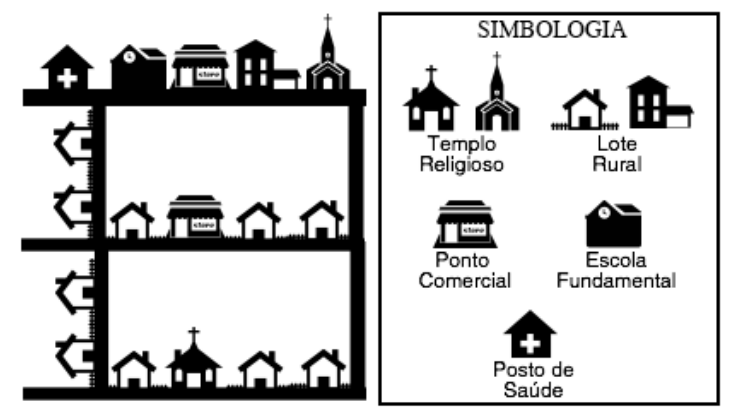

Fonte: Os autores

Figura 10 - Agrovila Israel, Moju-PA, é um exemplo de aglomerado de Nível D
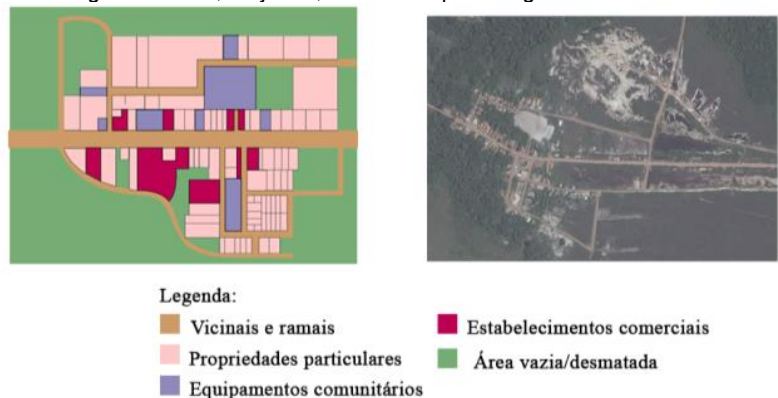

Estabelecimentos comerciais

- Área vazia/desmatada

Fonte: Os autores 
O quinto nível (Nível E) hierárquico conta com um sistema de ruas mais estruturada e diversas quadras, que abrigam usos diversos - moradias, pontos comerciais especializados (farmácias, lojas de móveis, supermercados), escolas de ensino fundamental $\left(1^{\mathrm{a}}\right.$ a $9^{\mathrm{a}}$ séries) e ensino médio, em alguns casos até mesmo unidades de ensino superior, e principalmente posto de saúde da família (Figura 11).

Figura 11 - Representação do Nível E da rede de aglomerados

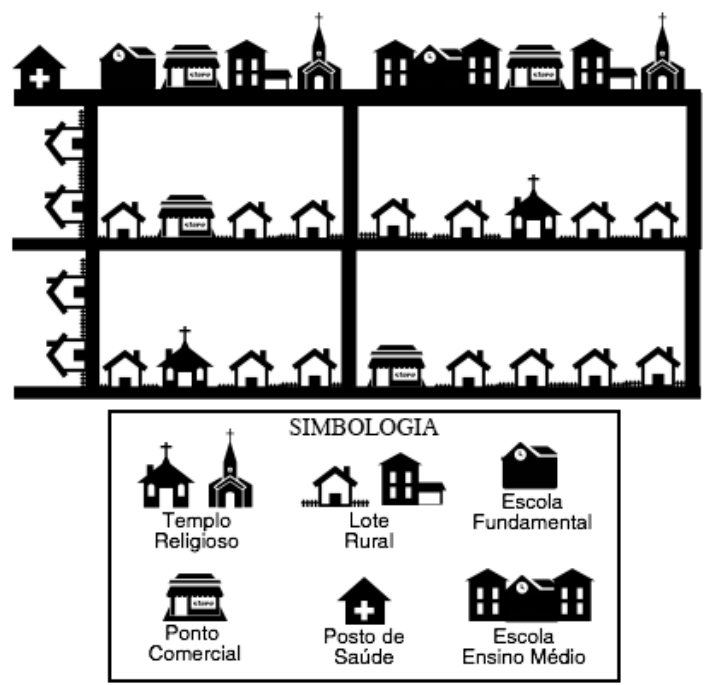

Fonte: Os autores

Os serviços de saúde e educação existentes nestes aglomerados os tornam pontos de polarização dentro da área rural, pois eles são acessados pela população dos demais níveis, como é o caso da Vila Olho D’água em Moju (Figura 12).

Figura 12 - Imagem de satélite mostrando a malha viária da Vila Olho D'água, Moju-PA

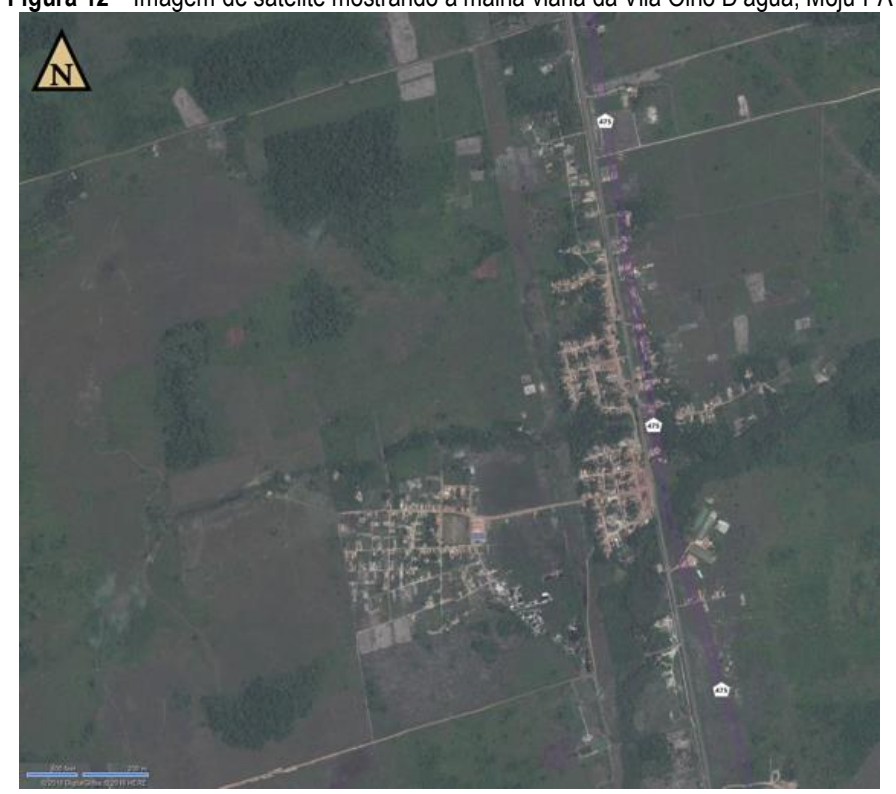

Fonte: Adaptado de BING MAPS, 2016
Há correspondência entre a posição do aglomerado na rede e as práticas de uso e ocupação do território introduzidas nos três períodos de colonização, traduzida na intensidade da dependência dos recursos da natureza, pela acessibilidade por rio ou estrada, pelo tipo de organização social, e de acesso à políticas públicas.

Os menores aglomerados sobrevivem principalmente a partir da base deixada pelo primeiro período colonial (1616 a 1850). A prática conjunta da coleta extrativa, caça e pesca que depende dos rios e florestas, aliada à agricultura (a roça) viabiliza a subsistência e a comercialização de excedentes por comerciantes volantes (o regatão do passado e o atravessador de hoje) (HÉBETTE; MOREIRA, 2004; SCHMINK; WOOD, 2012; SOUSA; MACEDO, 2011).

O segundo e o terceiro níveis da rede é herdeiro da colonização oficial do Governo do Estado do Pará iniciada em 1873, a das políticas de colonização do século XX, que procuraram superpor novas práticas às já existentes com a implantação de colônias: a) Japonesas, que introduziram na agricultura a produção de hortaliças para subsistência e de comodities para a venda, como a pimenta-do-reino em consorcio com outras plantas (Sistemas Agroflorestais $\mathrm{SAFs}$ ); e comunitariamente introduziram a prática do cooperativismo (como melhor exemplo tem-se a Cooperativa Agrícola Mista de Tomé-açu - CAMTA); b) de "sulistas" que reforçaram a prática da extração de madeira e c) as de nordestinos, reconhecidas pela produção bem sucedida em larga escala de farinha de mandioca na área Bragantina, comercializada em Belém e no Maranhão (HÉBETTE; ALVES; QUINTELA, 2004; HÉBETTE; MOREIRA, 2004; SCHMINK; WOOD, 2012).

O legado mais expressivo, no entanto, diz respeito à formação da própria rede de aglomerados (urbano-rurais), em decorrência da colonização oficial promovida pelo Instituto Nacional de Colonização e Reforma Agrária (INCRA), que continha proposta de urbanismo rural, desenvolvida pelo arquiteto José Geraldo Camargo, de uma rede de aglomerados que ofereceria à população de migrante acesso à terra, moradia e serviços públicos por meio de um conjunto hierarquizado de núcleos de caráter urbano: a tricotomia agrovila-agrópolis-rurópolis (VENTURA FILHO, 2004; CARDOSO; LIMA, 2009; MEDICILÂNDIA, 2014).

Nessa tricotomia, as agrovilas possuiriam em uma área de 100 ha lotes urbanos, equipamentos de uso coletivo e serviços como escola rural, centro comunitário, pequenos comércios, serviços e áreas de lazer (quadras de esporte e área verde com fins de praça). Cada agrovila seria capaz de assistir a 48 lotes rurais de 100ha. As agrópolis possuiriam, em uma área de 300 há, lotes urbanos e serviços e equipamentos de maior porte que aqueles 
existentes nas agrovilas. Nesses aglomerados contariam com posto de saúde, correios, telefones e escolas de segundo grau e serviços de apoio aos usuários da rodovia, ou seja, postos de gasolina, oficinas mecânicas, motéis, etc. As agrópolis apoiariam um conjunto máximo de 22 agrovilas, sendo que o ideal seria apoiar apenas de 8 a 10 agrovilas (Figura 13). Por fim as Rurópolis seriam núcleos urbanos de 20.000 habitantes, notadamente as sedes municipais já existentes que apoiariam os demais níveis da tricotomia com suas funções de centro cultural, social, comercial e administrativo em um raio de influência variável de 70 a $120 \mathrm{~km}$ (VENTURA FILHO, 2004; CARDOSO; LIMA, 2009).

A rede observada como resultado da pesquisa apresenta elementos da proposta do urbanismo rural tanto no que se refere à quantidade de níveis hierárquicos, quanto à sua composição (quantidade de serviços e equipamentos), como pode ser observado na Figura 14. Os aglomerados de Nível A e B estão sob a área de influência imediata dos aglomerados de Nível C e D, que por sua vez estão na área de influência dos aglomerados de Nível E.

Figura 13- Esquema da estrutura do Módulo de Colonização do INCRA imbuído das características do urbanismo rural de Camargo: posicionamento das agrovilas e agrópolis com exemplificação de suas respectivas áreas de influência

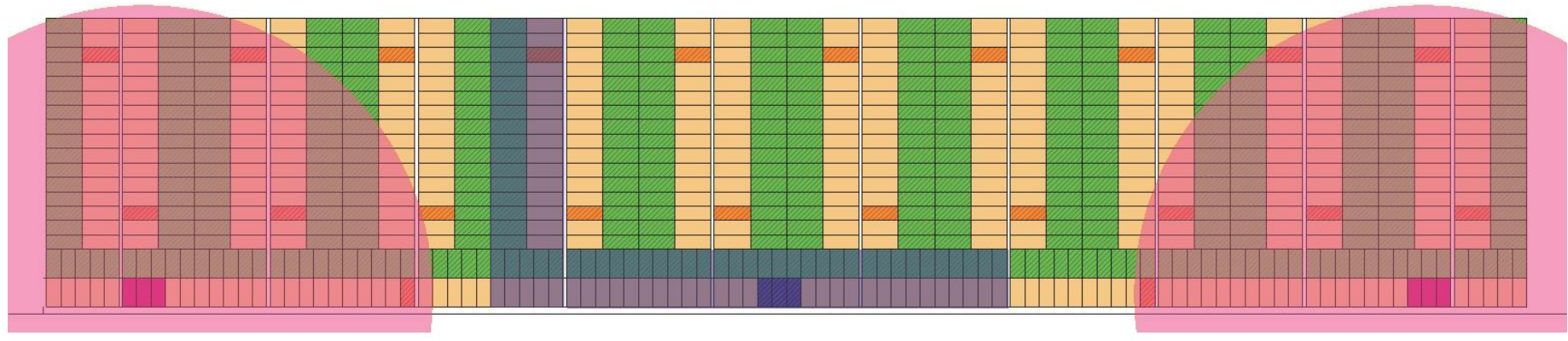

\section{Legenda}

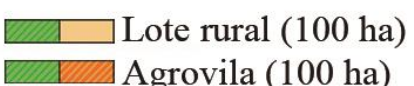
Agrovila (100 ha)

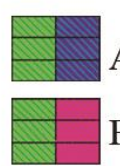

Agrovila (300 ha)

Futura Agrópolis (300 ha)
Área preservação

Área de agricultura geral

Área de influência da agrópolis $(10 \mathrm{~km})$ Área de influência da agrovila

Fonte: Adaptado de Ventura Filho (2004)

Figura 14 - Esquema de localização dos diversos níveis de aglomerados.

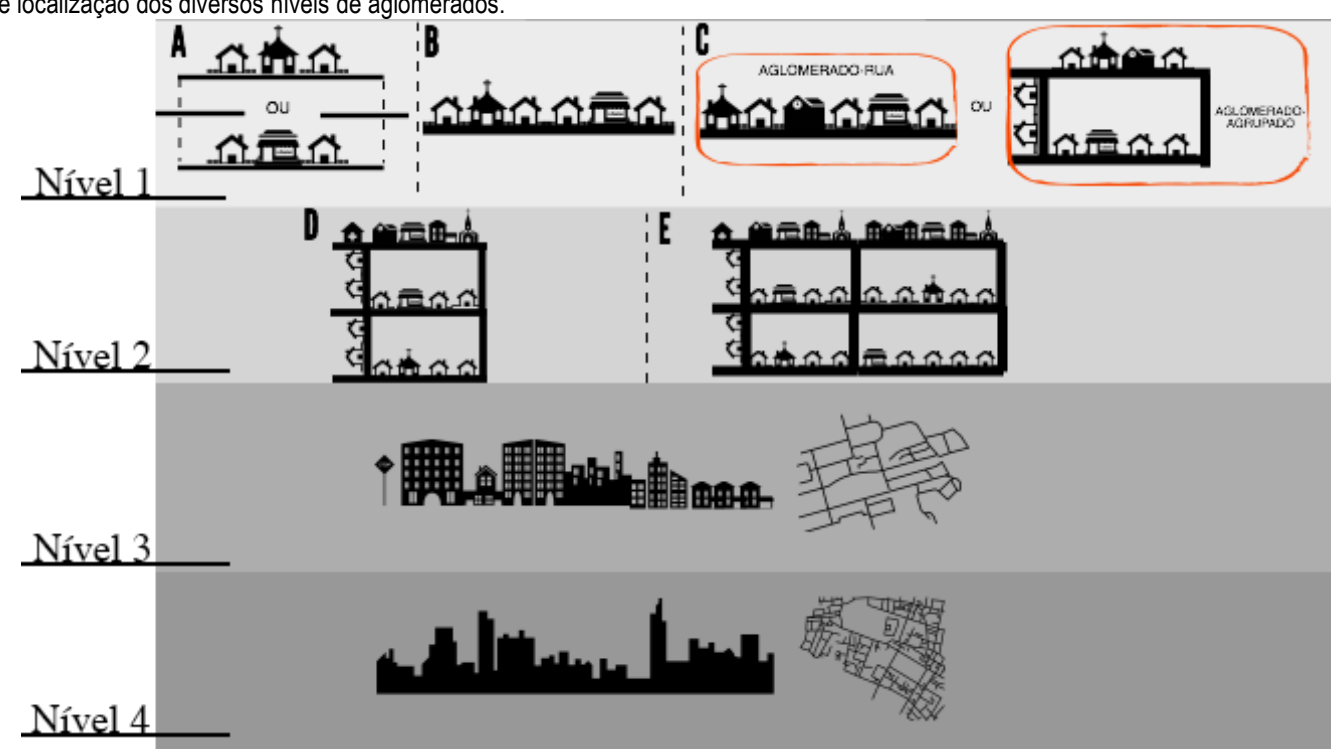


Estes legados influenciam características socioeconômicas de cada nível de aglomerado, como apresentado no Quadro 2.

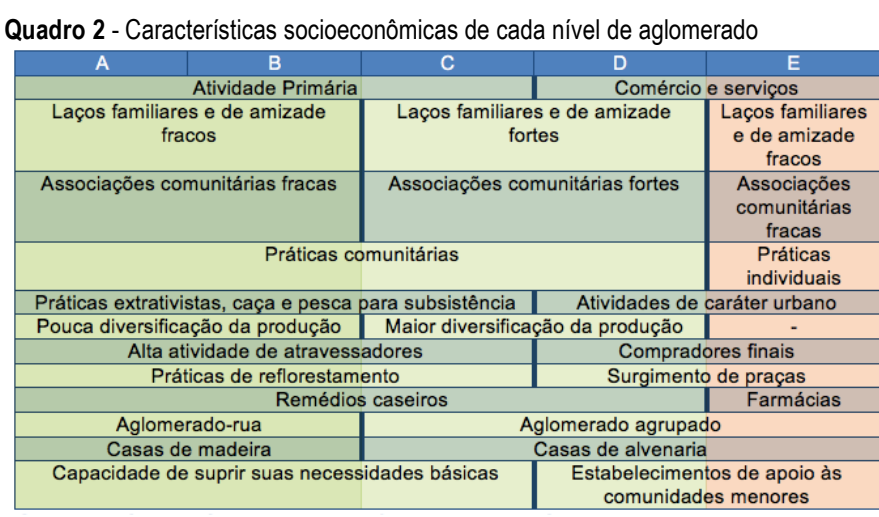

Fonte: Os autores

Nos níveis A e B a solução da subsistência e a saúde advém de atividades e práticas que dependem da natureza, e, portanto, da preservação da floresta e dos rios, nesses níveis existe pouca diversidade de produção para venda e a atuação dos atravessadores é forte. Também se percebe nestes dois níveis certa fragilidade quanto aos laços familiares e de amizade. Nas localidades estudadas os moradores desses níveis são mais individualistas e por conseguinte as associações de moradores são fracas, apesar disso existe o potencial para as práticas comunitárias, já que estes aglomerados são pequenos, o que teoricamente seria um ponto facilitador para reuniões comunitárias. Há maior conscientização dos moradores quanto a sustentabilidade e resiliência dos recursos naturais, dada a sua maior vulnerabilidade à escassez de peixes e caça.

Os níveis C e D aparecem como intermediários entre as práticas e modos de vida rural e as práticas urbanas observadas no Nível E. Esses níveis possuem laços familiares e de amizade mais fortes que os Níveis A e B, por conseguinte possuem associações comunitárias também fortes, e em alguns casos a parcela da produção destinada à venda é mais diversificada. Há casos de projetos de fomento à diversificação da renda (manufatura e iniciativas industriais) como a implantação de unidade beneficiadora de polpa de frutas. O nível $\mathrm{C}$ guarda características mais rurais, com práticas comunitárias, produção agrícola, extrativista, caça, pesca para subsistência e produção de remédios caseiros, que suprem as necessidades básicas de sua população; $O$ nível $D$ apresenta características urbanas, já vende sua produção agrícola para compradores finais e possui alguns estabelecimentos de apoio aos aglomerados dos níveis $\mathrm{A}$ e B.

O nível $\mathrm{E}$ corresponde aos aglomerados rurais que possuem características mais urbanas. São os maiores e possuem os principais estabelecimentos de apoio aos demais níveis. Contudo os laços familiares em geral tornaram-se fracos, há um progressivo fortalecimento de práticas individualistas que têm inviabilizado as associações comunitárias. A produção rural de grande parte dos moradores não é realizada em área contígua ao aglomerado, mas em propriedades localizadas em vicinais próximas. Comércio e serviços atendem os compradores finais e a prática dos remédios caseiros conta com forte concorrência do fácil acesso às farmácias que vendem remédios industrializados.

\section{Conclusão}

Conclui-se, portanto, que existe uma superposição de modos de subsistência e produção na área estudada. Velhas práticas são mantidas e mescladas a novas atividades, porém há tendência de desvalorização de práticas dependentes da natureza que viabilizam o sustento das populações mais isoladas. Observa-se a existência de um modo de vida e produção rural com grande potencial sustentável (por meio do manejo das áreas de floresta ou de reflorestamento através do extrativismo e de consórcios vegetais como os sistemas agroflorestais); uma prática sindical e cooperativada de grande potencial (que reflete a organização social e os laços familiares e de amizade que podem ser expandidos para parcerias entre aglomerados); e um padrão espacial em rede de aglomerados com diversos tipos morfológicos de ocupação rural.

Todas essas características indicam a necessidade de convergência de políticas ambientais, de produção rural e de acesso a serviços e equipamentos tradicionalmente considerados urbanos, mas que são demandados nas áreas rurais e instigam profissionais de diversas áreas a trabalharem para a melhoria de condições de vida da população tanto quanto para o aperfeiçoamento de formas de produção. Observa-se que a influência do modo de vida urbano intensifica o consumo (de produtos industriais e mesmo de alimentos) e enfraquece valores socioambientais nas comunidades mais isoladas. Essa realidade indica uma contramão em relação à inovação e aproveitamento dos potenciais oferecidos pela natureza na região. Historicamente o sucesso da produção rural esteva na capacidade de compreensão da interdependência entre população e natureza, que inclui a dispersão sócio espacial como característica intrínseca.

Espera-se com esse artigo iluminar a compreensão desse padrão socioespacial, e contribuir para o aperfeiçoamento de iniciativas de investimentos públicos e privados, visibilizando uma população que conhece os limites do território em que vive, mas enfrenta problemas para o exercício da cidadania como já é possível em áreas urbanas (acesso ao transporte público, à educação adequada, à segurança, à saúde). Tais disparidades contribuem para o estigma do universo rural como atrasado, e também para o 
crescente desconhecimento sobre a possibilidade de

fomento a ciclos virtuosos entre população e natureza.

\section{Agradecimentos}

Este artigo é um produto do projeto de pesquisa 'Avaliação de impactos sociais, econômicos e ambientais da cadeia de produção de óleo de palma' do Instituto Tecnológico Vale (ITV) e Munasinghe Institute for Development. Agradecemos o apoio da empresa Biopalma S.A., em especial aos membros do departamento socioambiental da empresa, Juliana Magalhães, Bruna Sousa, Javã da Silva, Ailson Monteiro, Charles Caldas e Maiane Pereira que nos proporcionaram o apoio logístico em nosso trabalho nas comunidades. As autoras agradecem as contribuições dos avaliadores para o resultado final desse artigo, ao apoio do CNPq, através de Bolsa de Produtividade, processo 309560/2015-2 e do ITV através de Bolsa de Pesquisa - mestrado.

\section{Notas}

(1) A Empresa Biopalma S.A. atua na região na plantação de palma e na produção de óleo de dendê para fabricação de biocombustível. Durante o desenvolvimento da pesquisa a empresa praticava o consórcio com agricultores familiares (plantação de dendê por parte dos pequenos produtores e compra dos frutos pela empresa). Nas comunidades onde a empresa atuava eram acompanhadas pelo Departamento Socioambiental da Empresa, que desenvolvia uma sistemática de grupos de trabalho com o objetivo de fortalecer as associações de moradores e o contato entre as comunidades e o poder público. A pesquisa empírica realizada se beneficiou do relacionamento existentes entre esse departamento e a população para organização das oficinas de produção da cartografia social e aprofundamento de conteúdos por meio de entrevistas.

\section{Referências}

ANTONUCCI, Denise et al. UN-HABITAT: 3 décadas de Atuação. Arquitextos, v.9, n. 107, abr. 2009. Disponível em: <http://www.vitruvius.com.br/revistas/read/arquitextos/09.107/56> acesso em 06/06/2016.

BECKER, Bertha. A urbe amazônida. Rio de Janeiro: Gramond, 2013. 86 p.

BESSA, Kelly. Estudos sobre a rede urbana: os precursores da teoria das localidades centrais. GeoTextos, vol. 8, n. 1, jul. 2012, pp. 147-165.

BING MAPAS. [Vila Olho D’água] 2¹5'7.95"S; 4847'30.71"W, Acesso em: 3 jun. 2016.

CAMARGO, José. Urbanismo Rural, Brasília: INCRA, 1973.

CARDOSO, Ana Cláudia; LIMA, José Julio. A influência do Governo Federal sobre cidades na Amazônia: os casos de Marabá e Medicilândia. Novos Cadernos NAEA, Belém, v.12, n. 1, p. 161-192, 2009. Doi: http://dx.doi.org/10.5801/ncn.v12i1.285

CASTRO, Edna. Urbanização, pluralidade e singularidade das cidades amazônicas. In: CASTRO, Edna (Org.). Cidades da floresta. São Paulo: Annablume, 2009. p. 11-40.

CHAMBOULEYRON, Rafael. Plantações, sesmarias e vilas. Uma reflexão sobre a ocupação da Amazônia seiscentista. Nuevo Mundo Mundos Nuevos, Debates, 2006, Disponível em: 〈https://nuevomundo.revues.org/2260\#text〉. Acesso em: 12 jun. 2013.

GUERRA, Gutemberg. Religião, Educação, futebol e mercado: elementos estruturantes da vida social em povoados da Amazonia. Belém: NEAD/UFPA, 2015 (mimeo).

HÉBETTE, Jean; ACEVEDO, Rosa. Colonização para quem? Belém: Falangola Offset/ Ufpa/naea, 1979. 173 p.

HÉBETTE, Jean; ALVES, Juliete M.; QUINTELA, Rosângela Sa S.. Parentesco, vizinhança e organização profissional na formação da frente pioneira amazônica. In: HÉBETTE, Jean (Org.). Cruzando a fronteira: 30 anos de estudo do campesinato na Amazônia. Belém: Ed.ufpa, 2004. p. 101-119. Volume 4: Um novo campesinato Amazônico. O papel das Instituições científicas e de seus pesquisadores.

HÉBETTE, Jean; MOREIRA, Edna Silva. A marcha do trabalhador do campo rumo à cidadania: domínio da terra e estrutura social no Pará. In: HÉBETTE, Jean (Org.). Cruzando a fronteira: 30 anos de estudo do campesinato na Amazônia. Belém: Ed.ufpa, 2004. p. 25-42. Volume 4: Um novo campesinato Amazônico. O papel das Instituições científicas e de seus pesquisadores. 
HOMMA, Alfredo Kingo Oyama. A agricultura nikkei e o desenvolvimento da agricultura na Amazônia. In: HOMMA, Alfredo Kingo Oyama et al (Org.). Imigração japonesa na Amazônia: contribuição na agricultura e vínculo com o desenvolvimento regional. Manaus: Edua, 2011. p. 339-375.

IBGE - INSTITUTO BRASILEIRO DE GEOGRAFIA E ESTATÍSTICA. Noções básicas de cartografia. Disponível em: <http://www.ibge.gov.br/home/geociencias/cartografia/manual_nocoes/elementos_representacao.html> Acesso em: 18 dez. 2014.

MEDICILÂNDIA. Medicilândia: histórico. Disponível em: 〈http://www.medicilandia.pa.gov.br/87/DadosMunicipais/> Acesso em: 10 dez. 2014.

MONTE-MOR, Roberto, Extended Urbanization and Settlement Patterns in Brazil: an Environmental Approach. In: Brenner, N. (org) Implosions/ Explosions: Towards a study of planetary urbanization. Berlim: Jovis, 2014, 109- 120.

PEREIRA, José Carlos Matos. A Urbanização da Amazônia e o papel das Cidades Médias na Rede Urbana Regional. In: CARDOSO, Ana Cláudia Duarte (Org.). O Rural e o Urbano na Amazônia: Diferentes olhares em perspectiva. Belém: Edufpa, 2006. p. 23-54.

PINHO, Carolina Moutinho Duque de. Análise das redes de localidades ribeirinhas amazônicas no tecido urbano estendido: uma contribuição metodológica. 2012. 156 f. Tese (Doutorado) - Curso de Curso de Pós-graduação em Sensoriamento Remoto, Instituto Nacional de Pesquisas Espaciais, São José dos Campos, 2012.

PINHO, Giselle Fernandes de. Estudo das Relações Entre Mobilidade da População e Acesso às Políticas Públicas em Moju e Acará - Pa. 2015. 204 f. Dissertação (Mestrado) - Curso de Mestrado Profissional em Uso Sustentável de Recursos Naturais em Regiões Tropicais, Instituto Tecnológico Vale, Belém, 2015.

SCHMINK, Marianne; WOOD, Charles H.. Conflitos sociais e a formação da Amazônia. Belém: Ed.ufpa, 2012. 489 p.

SOUSA, Rafael Benevides de; MACEDO, Cátia Oliveira. Comunidades camponesas no nordeste paraense: o caso de São Judas e Cravo. Revista Geografia, Londrina, v. 20, n. 2, p.115-128, maio/ago 2011. Bimestral. Disponível em: <http://www.uel.br/revistas/uel/index.php/geografia/article/view/7060 > . Acesso em: 23 jul. 2014.

VENTURA FILHO, Raul da Silva. A Floresta Urbanizada: a formação de núcleos urbanos na transamazônica, trecho Altamira Itaituba. 2004. 239 f. Tese (Doutorado) - Curso de Curso de Pós-graduação em Planejamento Urbano e Regional, Instituto de Pesquisa e Planejamento Urbano e Regional, Universidade Federal do Rio de Janeiro, Belém, 2004.

\section{${ }^{1}$ Giselle Fernandes de Pinho}

Arquiteta e Urbanista. Mestre em Uso Sustentável de Recursos Naturais no Trópico Úmido. Endereço postal: Rua Dr. Américo de Campos, 1265, chalé B, Bairro Cidade Universitária parte II, Campinas, SP, Brasil, 13083040

\section{Ana Cláudia Duarte Cardoso}

Arquiteta e Urbanista. Doutora em Arquitetura pela Oxford Brookes University UK). Endereço postal: Universidade Federal do Pará, Faculdade de Arquitetura e Urbanismo. Cidade Universitária, Rua Augusto Corrêa s/n, Bairro Guamá, Belém, PA, Brasil, 66075110 